\title{
Reproductive and hormonal factors in relation to survival and platinum resistance among ovarian cancer cases
}

\author{
Amy L Shafrir ${ }^{\star 1,2}$, Ana Babic ${ }^{3}$, Rulla M Tamimi ${ }^{1,2}$, Bernard A Rosner ${ }^{2,4}$, Shelley S Tworoger ${ }^{1,2}$ \\ and Kathryn L Terry ${ }^{1,5}$ \\ ${ }^{1}$ Department of Epidemiology, Harvard TH Chan School of Public Health, 677 Huntington Avenue, 9th Floor, Boston, MA 02115, \\ USA; ${ }^{2}$ Department of Medicine, Channing Division of Network Medicine, Brigham and Women's Hospital and Harvard Medical \\ School, 181 Longwood Avenue, Boston, MA 02115, USA; ${ }^{3}$ Department of Medical Oncology, Dana-Farber Cancer Institute and \\ Harvard Medical School, 450 Brookline Avenue, Boston, MA 02215, USA; ${ }^{4}$ Department of Biostatistics, Harvard TH Chan School of \\ Public Health, 677 Huntington Avenue, Boston, MA 02115, USA and ${ }^{5}$ Department of Obstetrics and Gynecology, Obstetrics and \\ Gynecology Epidemiology Center, Brigham and Women's Hospital and Harvard Medical School, 221 Longwood Avenue, Boston, \\ MA 02115, USA
}

Background: Ovarian cancer survival is poor, particularly for platinum-resistant cases. The previous literature on pre-diagnostic reproductive factors and ovarian cancer survival has been mixed. Therefore, we evaluated pre-diagnostic reproductive and hormonal factors with overall survival and, additionally, platinum-chemotherapy resistance.

Methods: We followed 1649 invasive epithelial ovarian cancer cases who were enrolled between 1992 and 2008 for overall mortality within the New England Case-Control Study and abstracted chemotherapy data on a subset $(n=449)$. We assessed prediagnostic reproductive and hormonal factors during in-person interviews. We calculated hazard ratios (HRs) using Coxproportional hazards models.

Results: We observed 911 all-cause deaths among 1649 ovarian cancer cases. Self-reported endometriosis and longer duration of hormone therapy use were associated with improved survival (HR: 0.72; $95 \%$ confidence interval (Cl): $0.54-0.94$ and HR, $\geqslant 5$ years vs never: $0.70 ; 95 \% \mathrm{Cl}$ : 0.55-0.90, respectively). Older age at menopause and menarche were associated with worse survival (HR, $\leqslant 50$ vs $>50$ years: 1.23 ; $95 \% \mathrm{Cl}: 1.03-1.46$ and $\mathrm{HR}, 13$ vs $<13$ years: 1.24 ; $95 \% \mathrm{Cl}$ : 1.06-1.44, respectively). We observed no association between oral contraceptive use, parity and tubal ligation, and overall survival. No significant associations were observed for any of the reproductive and hormonal factors and platinum resistance.

Conclusions: These results suggest that pre-diagnostic exposures such as endometriosis and HT use may influence overall survival among ovarian cancer patients.

Ovarian cancer is the deadliest gynaecological malignancy, accounting for an estimated 14240 deaths in US in 2016 (Siegel et al, 2016). Among women with ovarian cancer, only $45 \%$ will survive for 5 years after diagnosis, primarily because $60 \%$ of women are diagnosed at an advanced disease stage (Howlader et al,
2015). Furthermore, $\sim 80 \%$ of women will eventually relapse after first-line platinum and taxane-based chemotherapy (Howlader et al, 2015; NCI, 2015), and relapse within 6 months of ending treatment (platinum resistance) is associated with worse outcomes (Markman and Bookman, 2000; Jayson et al, 2014).

*Correspondence: Dr AL Shafrir; E-mail: amy.shafrir@mail.harvard.edu

Received 14 June 2016; revised 22 August 2016; accepted 6 September 2016; published online 4 October 2016

(c) 2016 Cancer Research UK. All rights reserved 0007 - 0920/16 
Thus, identifying factors associated with survival and chemoresistance may elucidate pathways involved in ovarian carcinogenesis and progression that could be explored in future research.

Increasing age, advanced disease stage, and poor tumour differentiation have been consistently associated with worse ovarian cancer survival (Baldwin et al, 2012; Anuradha et al, 2014; Urban et al, 2016). However, the literature has been mixed on the relationship between reproductive ovarian cancer risk factors and overall survival (Poole et al, 2016). One recent study noted improved survival for ovarian cancer patients with endometriosis (Melin et al, 2011); however, a 2014 meta-analysis of smaller studies reported no association after adjustment for covariates (Kim et al, 2014). Tubal ligation has been associated with an increased risk of ovarian cancer death in two small studies (Naik et al, 2000; Zhang and Holman, 2012), but not in larger studies (Mascarenhas et al, 2006; Nagle et al, 2008; Robbins et al, 2009). Use of menopausal hormone therapy (HT) before diagnosis was associated with a survival advantage in one study (Besevic et al, 2015), but not in other studies (Mascarenhas et al, 2006; Nagle et al, 2008; Wernli et al, 2008; Felix et al, 2015). Inconsistencies across studies may be driven by small sample sizes.

In this study, we used the large, population-based New England Case-Control (NECC) study to examine the association between pre-diagnostic reproductive and hormonal factors and overall survival among 1649 ovarian cancer cases. We had detailed characterisation of many pre-diagnosis exposures as well as data on tumour characteristics and treatment. In addition, given the particularly poor survival among patients with platinum resistance, we evaluated associations of reproductive and hormonal factors with platinum resistance among 449 ovarian cancer cases who were treated with platinum therapy and had information on relapse during the study interval.

\section{MATERIALS AND METHODS}

Study population. The NECC Study is a population-based study of ovarian cancer conducted in Eastern Massachusetts and New Hampshire. Data included in this analysis come from three enrolment phases (1992-1997, 1998-2002, 2003-2008). Details of enrolment into the three study phases have been described previously (Vitonis et al, 2011). Briefly, 3957 women diagnosed with incident ovarian cancer in Eastern Massachusetts or New Hampshire were identified through hospital tumour boards and statewide cancer registries. Exclusion criteria for the ovarian cancer cases included: $<18$ years old, moved, had no phone, did not speak English, died, or their physician declined permission to contact them. Of the ovarian cancer cases identified, 78\% were eligible and 2203 enroled in the study. Each participant provided a signed informed consent and the study was approved by the institutional review boards at Brigham and Women's Hospital and Dartmouth Medical School.

Case outcomes. A gynaecological pathologist reviewed the pathology reports for all cases to classify ovarian tumours by histology (serous, endometrioid, mucinous, clear cell, other), grade $(1,2,3)$, and FIGO stage (I, II, III, IV). Among a subset of women $(n=881)$ diagnosed at Brigham and Women's Hospital, Boston, MA, USA and Massachusetts General Hospital, Boston, MA, USA, we abstracted data on chemotherapy, residual disease, and ovarian cancer recurrence. Information was collected on first-line adjuvant chemotherapy, including each chemotherapy drug the woman received and the therapy start and end dates. Medical records up to July 2015, when available, were searched for evidence of ovarian cancer recurrence. Information was also collected on the size of residual disease after the initial debulking surgery and response to chemotherapy (complete, partial, poor/limited, stable disease, unknown/other). Women were considered optimally debulked if they had $<2 \mathrm{~cm}$ of residual disease remaining after their initial surgery. Date of death for cases was collected primarily through the Social Security Death Index and also from voter and census data and obituaries.

Assessment of pre-diagnostic exposure and covariate information. During in-person interviews, participants recalled detailed information on lifestyle, reproductive factors, medical history, and body size at least 1 year prior to diagnosis. In analyses on parity, pregnancies lasting 6 months or longer were included. Age at first birth was calculated using the date of the first pregnancy minus date of birth, whereas age at last birth was calculated using the date of the last pregnancy. Women were classified as having menstrual cycle irregularity if they never had regular menstrual cycles. Women reported each oral menopausal HT they had used including the type and duration of use, except in phase 1 of the study, which was excluded from this analysis. Self-reported endometriosis included endometriosis discovered as a cause of infertility. Women were classified as postmenopausal before their diagnosis if (1) their periods had stopped naturally, or (2) they had a hysterectomy or medical menopause and were older than 60 years. Women were classified as having uncertain menopause status if (1) they had a hysterectomy without an oophorectomy and were not yet 60 years old, or (2) their periods were still occurring due to HT use. Age at menopause was considered only for women who reported that their periods had stopped naturally. Ovulatory years were calculated as the age at natural menopause (or current age for premenopausal women) minus age at menarche with subtraction of OC duration and 1 year for each pregnancy. Finally, body mass index (BMI) was calculated as weight in kilograms divided by height in metres squared.

Statistical analyses. We included 1649 invasive epithelial ovarian cancer cases in our main survival analyses. Cox-proportional hazards model was used to calculate hazard ratios (HRs) and $95 \%$ confidence intervals (CI) for the association of each reproductive and hormonal factor with overall death, with years since ovarian cancer diagnosis used as the time scale. Cases contributed persontime from the date of ovarian cancer diagnosis until death or the end of follow-up in February 2015. In the platinum-resistance analyses, we included 449 cases with a complete response to platinum-based chemotherapy and information on ovarian cancer recurrence. Logistic regression was used to calculate odds ratios (OR) and 95\% CI for the association of each reproductive and hormonal factor with platinum resistance. Cases with a complete response to platinum-based chemotherapy and an ovarian cancer recurrence with 6 months of ending platinum-based chemotherapy were classified as platinum resistant. Cases with a complete response to platinum-based chemotherapy and no recurrence or a recurrence $>6$ months after completing chemotherapy were considered non-platinum resistant (i.e., platinum sensitive).

Our initial statistical models adjusted for age at diagnosis (years), year of diagnosis, state of residence (MA, NH), menopausal status (premenopausal, postmenopausal, uncertain menopause status), smoking status (current, past, never), BMI $\left(\mathrm{kg} \mathrm{m}^{-2}\right)$, OC use (ever, never), and parity (ever, never). We included reproductive factors in our initial models to account for possible confounding by pre-diagnostic factors as the association between reproductive and hormonal factors with survival among ovarian cancer cases is not clear. We then we evaluated a second model additionally adjusting for tumour stage (I/II, III/IV), grade (1, 2, 3, unknown), histology (serous, endometrioid, mucinous, clear cell, other), and debulking status (optimal debulking, nonoptimal debulking, unknown). The fully adjusted models further accounted for chemotherapy (no chemotherapy, platinum and taxol chemotherapy, chemotherapy other than platinum and taxol, unknown chemotherapy type) in the overall survival analysis. 
We choose to adjust for prognostic characteristics, such as tumour histology, to assess if the associations observed were driven by the characteristics of the tumour that developed or were independent of these factors. In the platinum analysis, histology was collapsed into serous $v s$ non-serous.

For the overall survival analysis, we performed a number of sensitivity analyses which included restricting to high-grade serous cases, excluding cases with stage IV disease, and restricting to cases with stage III disease. As the cause of death was not known for the majority of women, we restricted to the first 5 years of follow-up as most deaths are likely to be due to ovarian cancer during this time period. We tested for effect modification by study phase (1992-1997, 1998-2002, 2003-2008), age at diagnosis ( $\leqslant 50$ years $v s>50$ years), and histology (serous $v s$ non-serous) using a likelihood ratio test. In addition, as we observed strong associations for endometriosis, menstrual cycle irregularity, age at menarche, and age at natural menopause with overall survival, we stratified by tumour histology, grade, and stage.

In sensitivity analyses for the platinum-resistance analysis, we included all ovarian cancer cases treated with platinum chemotherapy and with a known end date of their treatment irrespective of their response to the platinum treatment. In these sensitivity analyses, we included a third model with additional adjustment for maintenance therapy (no, yes, unknown).

All analyses were performed using SAS version 9.3 (SAS Institute, Cary, NC, USA). $P$-values were two-sided and considered statistically significant if $<0.05$.

\section{RESULTS}

Study population. Among 1649 invasive epithelial ovarian cancer cases, we observed 911 all-cause deaths over an average follow-up of 7.6 years (s.d. 5.9 years). The average age at diagnosis among cases that died was 58 years compared with 52 years among cases who survived during follow-up (Table 1). Cases who died were less likely to report pre-diagnostic OC use (47 vs 59\%) and more likely to be parous (75 vs 64\%). In addition, women who died were more likely to be diagnosed with high-grade (72 vs 42\%), and serous (76 vs 37\%) tumours compared with women who did not die during follow-up.

Among the 449 ovarian cancer cases included in the platinumresistance analysis (Table 1$), 47(10.5 \%)$ had a recurrence within the first 6 months of ending platinum-based chemotherapy (platinum resistant). The majority of platinum-resistant cases, $79 \%$, had a serous tumour compared with only $54 \%$ of platinumsensitive cases. In addition, platinum-resistant cases were more likely to be older, have a high-grade tumour, be parous and be postmenopausal at diagnosis compared with platinum-sensitive cases.

Overall survival. Pre-diagnostic parity and tubal ligation were significantly positively associated with overall survival before adjusting for tumour characteristics; however, after adjustment for tumour histology in particular, the associations were substantially attenuated (Table 2). Further, pre-diagnostic induced abortion was not significantly associated with survival, but women with at least one miscarriage had a $17 \%$ (95\% CI: $1.00-1.36$ ) increased risk of death compared with women who never reported a miscarriage. In the fully adjusted analyses, increasing age at menarche was associated with an increased risk of death with a HR of 1.24 (95\% CI: 1.06-1.44) for an age at menarche of 13 years vs $<13$ years. In addition, women who were older than 50 years at natural menopause before diagnosis had a 23\% (95\% CI: $1.03-1.46)$ increased risk of death compared with women who were 50 years or younger at menopause. There was a significant relationship between menstrual cycle irregularity and overall survival (HR: 0.73;
95\% CI: 0.54-0.99). Women who reported ever having prediagnostic endometriosis were $29 \%$ (95\% CI: 0.54-0.94) less likely to die after their ovarian cancer diagnosis compared with women without endometriosis. Although pre-diagnostic postmenopausal use of HT was not associated with overall death (HR: 0.89; 95\% CI: 0.73-1.08), longer duration of HT use was associated with a decreased risk of death (HR: 0.79 ; $95 \%$ CI: $0.55-0.90$ for $>5$ years vs never). No significant associations were observed for prediagnostic breastfeeding, oral contraceptive use, or ovulatory years as well as age at first and last birth and IUD use with overall survival (data not shown).

Stratified analyses. There was significant heterogeneity between age at menarche and histology (Table 3). The increased risk of death for women with an age at menarche $>13$ years compared with $<13$ years was only observed among women with highgrade serous, endometrioid, and clear cell ovarian tumours and not among women with low-grade serous tumours $(P$-heterogeneity $=0.01)$. Although based on a small sample size, the reduced risk of death among women with endometriosis and never regular menstrual cycles was consistent across tumour histology $(P$-heterogeneity $=0.27$ and 0.20 , respectively). The HRs for endometriosis, menstrual cycle irregularity, age at natural menopause, and age at menarche did not vary by FIGO stage at diagnosis (data not shown).

Sensitivity analyses. In sensitivity analyses, there were no significant interactions between any of the exposures and study phase (data not shown). There was a significant interaction between menopausal status and tumour histology $(P$-heterogeneity $=0.02)$, although menopausal status was not significantly associated with risk of death for serous or non-serous tumours. In addition, we observed significant interactions of age at diagnosis with parity, menopausal status and menstrual cycle irregularity $(P$-heterogeneity $<0.04)$. For example, there was a significant inverse association with death for parity among women aged $>50$ years (HR: $0.81 ; 95 \%$ CI: $0.67-0.98$ ), but not $\leqslant 50$ years (HR: 1.08 ; 95\% CI: 0.79-1.47). Conversely, the inverse association for menstrual cycle irregularity was only observed among women aged $\leqslant 50$ years (data not shown).

Overall, associations were slightly stronger among women interviewed within 1 year of diagnosis, except for endometriosis, age at natural menopause, and 5 or more years of HT use, which were in the same direction as the full analysis but no longer significant. Similarly, results were generally stronger in analyses restricted to the first 5 years of follow-up (data not shown), including a significant association for ovulatory years (HR, top vs bottom quartile: 1.32; 95\% CI: 1.01-1.73). Results were substantially unchanged when excluding stage IV disease or restricting to stage III tumours, but slightly attenuated, although in the same direction, when restricting to high-grade serous tumours (data not shown).

Platinum resistance. Among women who had a complete response to platinum-based chemotherapy, no significant associations were observed with platinum resistance (Table 4). Although non-significant, ORs for age at menarche $(\mathrm{OR}, \geqslant 13$ vs $<13$ years: 1.42; 95\% CI: 0.75-2.71), age at natural menopause (OR, $>50$ vs $\leqslant 50$ years: 1.54 ; $95 \%$ CI: $0.68-3.48$ ), and endometriosis (OR: 0.33 ; 95\% CI: $0.07-1.50$ ) are all in the same direction as the hazard estimates for the overall survival analysis. Overall the sensitivity analyses including all ovarian cancer cases irrespective of their response to platinum treatment were similar to the main results for cases with a complete response (Supplementary Table 1), with the exception of menopausal status. Postmenopausal women were at greater risk of platinum resistance compared with premenopausal women (OR: 2.27 ; 95\% CI: $1.06-4.84$ ). 
Table 1. Characteristics of NECC invasive epithelial ovarian cancer cases for the survival analysis $(N=1649)$ and the platinumresistance analysis $(N=449)$

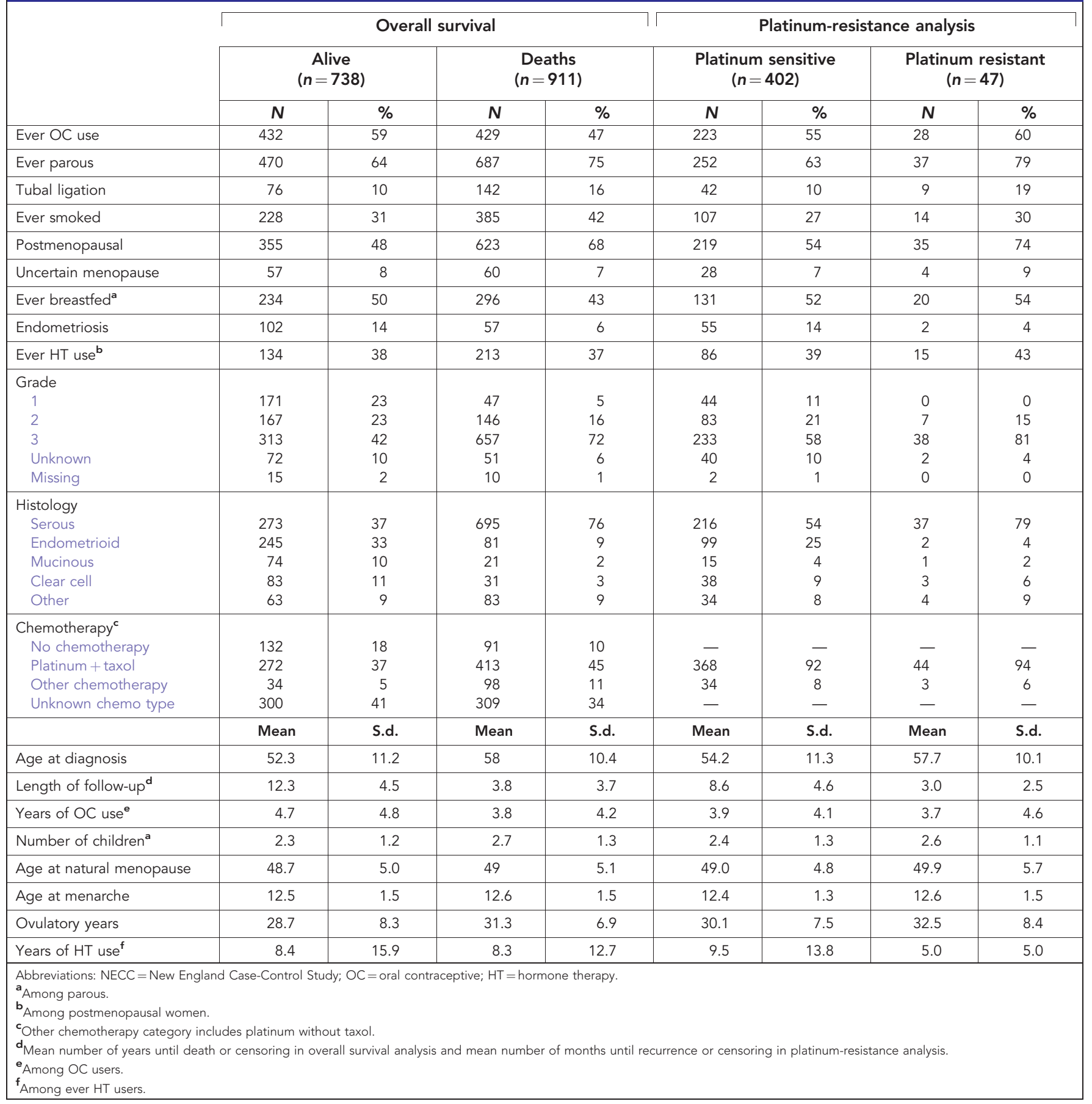

\section{DISCUSSION}

In one of the largest studies to date, we investigated the association between pre-diagnostic reproductive and hormonal factors and overall survival among 1649 ovarian cancer cases in the NECC Study with careful control for reproductive, tumour, and treatment characteristics. Endometriosis, menstrual cycle irregularity, and longer duration of HT use were associated with improved survival whereas spontaneous miscarriage, older age at menarche, and older age at natural menopause were associated with a worse prognosis. Consistent with the majority of previous research we did not observe any associations between survival and OC use, parity, breastfeeding, tubal ligation, and ovulatory years (Jacobsen et al, 1993; Kjaerbye-Thygesen et al, 2006; Mascarenhas et al, 2006; Nagle et al, 2008; Yang et al, 2008; Robbins et al, 2009; Zhang and Holman, 2012; Besevic et al, 2015). In the first analysis of its kind, we did not observe any significant associations between reproductive and hormonal factors with platinum resistance, although power was limited by a smaller sample size of only 449 ovarian cancer cases with complete response to platinum chemotherapy.

Endometriosis has been consistently associated with an increased risk of ovarian cancer, particularly for endometrioid and clear cell tumours (Pearce et al, 2012). Interestingly, in our study, we observed a $29 \%$ decreased risk of death among ovarian cancer cases with self-reported endometriosis before diagnosis. 
Table 2. Association between reproductive and hormonal factors and overall survival among invasive ovarian cancer cases in the NECC $(N=1649)$

\begin{tabular}{|c|c|}
\hline $\begin{array}{c}\text { Reproductive } \\
\text { characteristics model }^{\mathrm{a}}\end{array}$ & $\begin{array}{l}\text { Reproductive and tumour } \\
\text { characteristics model }{ }^{\mathrm{b}}\end{array}$ \\
\hline
\end{tabular}

\begin{tabular}{|c|c|c|c|c|c|c|c|c|}
\hline & Total $(n)$ & $\begin{array}{c}\text { Fatal } \\
\text { cases }(n)\end{array}$ & HR & $95 \% \mathrm{Cl}$ & $\mathrm{HR}$ & $95 \% \mathrm{Cl}$ & $\mathrm{HR}$ & $95 \% \mathrm{Cl}$ \\
\hline \multicolumn{9}{|l|}{ Parity } \\
\hline Nulliparous & 492 & 224 & 1.00 & (ref.) & 1.00 & (ref.) & 1.00 & (ref.) \\
\hline Parous & 1157 & 687 & 1.19 & $(1.02-1.40)$ & 0.89 & $(0.76-1.05)$ & 0.88 & $(0.75-1.04)$ \\
\hline Nulliparous & 492 & 224 & 1.00 & (ref.) & 1.00 & (ref.) & 1.00 & (ref.) \\
\hline $1-2$ children & 683 & 370 & 1.17 & $(0.98-1.38)$ & 0.90 & $(0.75-1.07)$ & 0.88 & $(0.74-1.05)$ \\
\hline 3-4 children & 386 & 254 & 1.21 & $(1.00-1.47)$ & 0.87 & $(0.72-1.06)$ & 0.87 & $(0.72-1.06)$ \\
\hline $5+$ children & 88 & 63 & 1.33 & $(0.99-1.79)$ & 0.97 & $(0.72-1.31)$ & 0.97 & $(0.72-1.31)$ \\
\hline \multicolumn{9}{|c|}{ Breastfeeding $^{d}$} \\
\hline Never & 625 & 390 & 1.00 & (ref.) & 1.00 & (ref.) & 1.00 & (ref.) \\
\hline Ever & 530 & 296 & 1.03 & $(0.88-1.21)$ & 1.00 & $(0.85-1.17)$ & 1.00 & $(0.85-1.17)$ \\
\hline \multicolumn{9}{|c|}{ Oral contraceptive use } \\
\hline Never & 788 & 482 & 1.00 & (ref.) & 1.00 & (ref.) & 1.00 & (ref.) \\
\hline Ever & 861 & 432 & 1.02 & $(0.88-1.18)$ & 1.07 & $(0.92-1.23)$ & 1.06 & $(0.91-1.23)$ \\
\hline Never & 788 & 482 & 1.00 & (ref.) & 1.00 & (ref.) & 1.00 & (ref.) \\
\hline$<1$ years & 187 & 104 & 1.07 & $(0.86-1.33)$ & 1.18 & $(0.95-1.47)$ & 1.16 & $(0.93-1.46)$ \\
\hline 1 to $<5$ years & 375 & 190 & 1.07 & $(0.89-1.28)$ & 1.09 & $(0.91-1.31)$ & 1.09 & $(0.91-1.31)$ \\
\hline 5 to $<10$ years & 193 & 96 & 1.00 & $(0.80-1.26)$ & 1.03 & $(0.82-1.30)$ & 1.01 & $(0.80-1.28)$ \\
\hline $10+$ years & 106 & 67 & 0.76 & $(0.54-1.06)$ & 0.84 & $(0.60-1.17)$ & 0.83 & $(0.60-1.16)$ \\
\hline \multicolumn{9}{|l|}{ Tubal ligation } \\
\hline Never & 1431 & 769 & 1.00 & (ref.) & 1.00 & (ref.) & 1.00 & \\
\hline Ever & 218 & 142 & 1.24 & $(1.03-1.49)$ & 1.01 & $(0.84-1.22)$ & 1.03 & $(0.85-1.24)$ \\
\hline \multicolumn{9}{|c|}{ Age at menarche $e^{e}$} \\
\hline$<13$ years & 801 & 422 & 1.00 & (ref.) & 1.00 & (ref.) & 1.00 & (ref.) \\
\hline 13 years & 502 & 290 & 1.15 & $(0.98-1.33)$ & 1.25 & $(1.07-1.46)$ & 1.24 & $(1.06-1.44)$ \\
\hline$>13$ years & 339 & 194 & 1.10 & $(0.92-1.30)$ & 1.22 & $(1.02-1.45)$ & 1.20 & $(1.01-1.43)$ \\
\hline \multicolumn{9}{|c|}{ Menopausal status at diagnosis ${ }^{f}$} \\
\hline Premenopausal & 554 & 228 & 1.00 & (ref.) & 1.00 & (ref.) & 1.00 & (ref.) \\
\hline Postmenopausal & 978 & 623 & 1.23 & $(0.97-1.56)$ & 1.05 & $(0.83-1.33)$ & 1.05 & $(0.83-1.33)$ \\
\hline \multicolumn{9}{|c|}{ Age at natural menopause ${ }^{g}$} \\
\hline$\leqslant 50$ years & 525 & 319 & 1.00 & (ref.) & 1.00 & (ref.) & 1.00 & (ref.) \\
\hline$>50$ years & 353 & 235 & 1.23 & $(1.04-1.47)$ & 1.24 & $(1.04-1.47)$ & 1.23 & $(1.03-1.46)$ \\
\hline \multicolumn{9}{|c|}{ Ovulatory years $^{h}$} \\
\hline$<26.5$ years & 366 & 150 & 1.00 & (ref.) & 1.00 & (ref.) & 1.00 & (ref.) \\
\hline $26.5-<32$ years & 357 & 203 & 1.19 & $(0.96-1.49)$ & 1.10 & $(0.87-1.37)$ & 1.11 & $(0.88-1.38)$ \\
\hline $32-35$ years & 314 & 183 & 1.16 & $(0.92-1.47)$ & 1.09 & $(0.85-1.36)$ & 1.08 & $(0.86-1.37)$ \\
\hline$>35$ years & 387 & 240 & 1.20 & $(0.95-1.52)$ & 1.14 & $(0.90-1.44)$ & 1.15 & $(0.91-1.45)$ \\
\hline \multicolumn{9}{|c|}{ Hormone therapy use ${ }^{i}$} \\
\hline Never & 451 & 265 & 1.00 & (ref.) & 1.00 & (ref.) & 1.00 & (ref.) \\
\hline Ever & 302 & 174 & 0.90 & $(0.74-1.10)$ & 0.88 & $(0.73-1.08)$ & 0.89 & $(0.73-1.08)$ \\
\hline Never & 451 & 265 & 1.00 & (ref.) & 1.00 & (ref.) & 1.00 & (ref.) \\
\hline$<5$ years & 142 & 85 & 1.04 & $(0.81-1.33)$ & 1.21 & $(0.94-1.55)$ & 1.21 & $(0.94-1.56)$ \\
\hline$\geqslant 5$ years & 160 & 89 & 0.80 & $(0.63-1.02)$ & 0.70 & $(0.54-0.90)$ & 0.70 & $(0.55-0.90)$ \\
\hline \multicolumn{9}{|c|}{ Miscarriage and induced abortion } \\
\hline Never & 1104 & 588 & 1.00 & (ref.) & 1.00 & (ref.) & 1.00 & (ref.) \\
\hline Ever & 545 & 323 & 1.14 & $(0.99-1.31)$ & 1.11 & $(0.97-1.28)$ & 1.10 & $(0.96-1.27)$ \\
\hline \multicolumn{9}{|c|}{ Menstrual cycles } \\
\hline Regular & 1555 & 866 & 1.00 & & 1.00 & (ref.) & 1.00 & (ref.) \\
\hline Irregular & 94 & 45 & 0.81 & $(0.60-1.09)$ & 0.74 & $(0.55-1.01)$ & 0.73 & $(0.54-0.99)$ \\
\hline \multicolumn{9}{|l|}{ Endometriosis } \\
\hline Never & 1490 & 854 & 1.00 & (ref.) & 1.00 & (ref.) & 1.00 & (ref.) \\
\hline Ever & 159 & 57 & 0.60 & $(0.45-0.78)$ & 0.72 & $(0.55-0.95)$ & 0.72 & $(0.54-0.94)$ \\
\hline \multicolumn{9}{|c|}{ 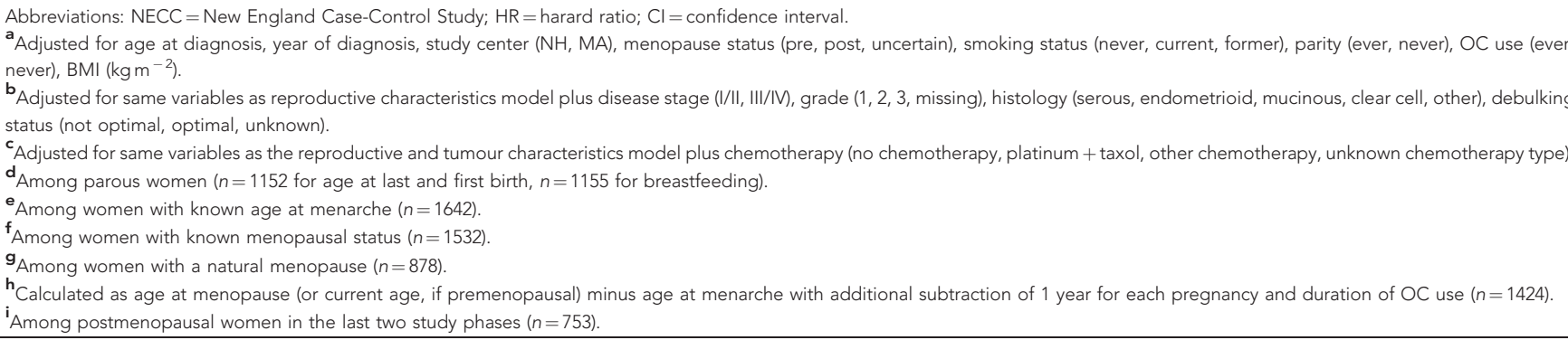 } \\
\hline
\end{tabular}


Table 3. Association between endometriosis and overall survival among invasive ovarian cancer cases by tumour histology and stage in the NECC $(N=1345)^{\mathrm{a}}$

\begin{tabular}{|c|c|c|c|c|}
\hline \multicolumn{4}{|c|}{ Reproductive and tumour characteristics model ${ }^{b}$} & \multirow[b]{3}{*}{$P$ het $^{c}$} \\
\hline & High-grade serous & Low-grade serous & Endometrioid and clear cell & \\
\hline & $\begin{array}{c}\text { HR }(95 \% \mathrm{Cl}) \\
\text { (total } n / \text { fatal cases } n)\end{array}$ & $\begin{array}{c}\text { HR }(95 \% \mathrm{Cl}) \\
\text { (total } n / \text { fatal cases } n \text { ) }\end{array}$ & $\begin{array}{c}\text { HR }(95 \% \mathrm{Cl}) \\
\text { (total } n / \text { fatal cases } n \text { ) }\end{array}$ & \\
\hline \multicolumn{5}{|c|}{ Age at menarche } \\
\hline $\begin{array}{l}<13 \text { years } \\
\geqslant 13 \text { years }\end{array}$ & $\begin{array}{l}1.00 \text { (ref.) (341/237) } \\
1.44(1.21-1.71)(395 / 310)\end{array}$ & $\begin{array}{l}1.00 \text { (ref.) }(90 / 63) \\
0.73(0.48-1.11)(76 / 45)\end{array}$ & $\begin{array}{l}1.00 \text { (ref.) (226/46) } \\
1.30(0.87-1.92)(212 / 65)\end{array}$ & 0.01 \\
\hline \multicolumn{5}{|c|}{ Age at natural menopause } \\
\hline $\begin{array}{l}\leqslant 50 \text { years } \\
>50 \text { years }\end{array}$ & $\begin{array}{l}1.00 \text { (ref.) }(277 / 210) \\
1.14(0.91-1.42)(167 / 130)\end{array}$ & $\begin{array}{l}1.00 \text { (ref.) (42/28) } \\
1.43(0.80-2.56)(43 / 34)\end{array}$ & $\begin{array}{l}1.00 \text { (ref.) }(108 / 33) \\
2.45(1.33-4.50)(106 / 30)\end{array}$ & 0.20 \\
\hline \multicolumn{5}{|c|}{ Endometriosis } \\
\hline $\begin{array}{l}\text { Never } \\
\text { Ever }\end{array}$ & $\begin{array}{l}1.00 \text { (ref.) (687/517) } \\
0.78(0.54-1.12)(51 / 32)\end{array}$ & $\begin{array}{l}1.00 \text { (ref.) }(150 / 101) \\
0.39(0.18-0.82)(17 / 8)\end{array}$ & $\begin{array}{l}1.00 \text { (ref.) (364/99) } \\
0.68(0.37-1.24)(86 / 13)\end{array}$ & 0.27 \\
\hline \multicolumn{5}{|c|}{ Menstrual cycles } \\
\hline $\begin{array}{l}\text { Regular } \\
\text { Irregular }\end{array}$ & $\begin{array}{l}1.00 \text { (ref.) (701/524) } \\
0.68(0.45-1.02)(37 / 25)\end{array}$ & $\begin{array}{l}1.00 \text { (ref.) (156/103) } \\
0.83(0.35-1.93)(11 / 6)\end{array}$ & $\begin{array}{l}1.00 \text { (ref.) (412/107) } \\
0.60(0.24-1.49)(28 / 5)\end{array}$ & 0.80 \\
\hline \multicolumn{5}{|c|}{ 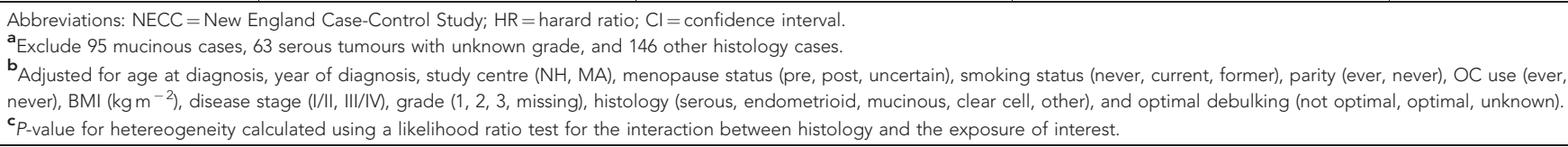 } \\
\hline
\end{tabular}

Although endometriosis-associated ovarian cancers (endometrioid, clear cell, and low-grade serous) are less aggressive than high-grade serous disease, our results suggested that the association was independent of tumour histology and disease stage, and remained after adjustment for debulking, tumour characteristics, and chemotherapy. Prior research in this area has been mixed. A recent meta-analysis of seven studies observed improved survival for women with endometriosis in univariate analyses, but the association was attenuated among the four studies that controlled for age and grade (Kim et al, 2014). More recent studies observed improved survival for women with endometriosis in univariate analyses, but not after adjusting for confounders (Garrett et al, 2013; Noli et al, 2013; Wang et al, 2013); however, the majority of these studies had small sample sizes, limiting power particularly in multivariate analyses. The largest study to date of endometriosis and survival was based within a Swedish registry and reported an improved prognosis among ovarian cancer patients with endometriosis (HR: 0.81; 95\% CI: 0.65-1.01) (Melin et al, 2011). However, this association was attenuated with adjustment for tumour histology and stage among a small subset of the cases with tumour characteristics data $(n=218)$. With 1649 ovarian cancer cases, ours is the largest study to date to assess endometriosis and survival with adjustment for tumour characteristics. It is likely that inconsistencies for this association are largely driven by small sample sizes, supporting a consortial approach.

The biological mechanism underlying the potential association between endometriosis and overall survival among ovarian cancer patients is unclear, but may involve differences in the immunological microenvironment within the peritoneal cavity of women with endometriosis (Gazvani and Templeton, 2002). In addition, ovarian tumours among women with endometriosis may be more likely to express progesterone receptors (PR) as endometriosis lesions have been reported to express PR (Attia et al, 2000). The expression of PR is associated with improved survival, particularly among endometrioid and high-grade serous ovarian cancer cases (Sieh et al, 2013). However, the expression of PR does not explain the decreased risk of death associated with endometriosis among clear cell tumours, which are generally PR negative (Hecht et al, 2009). Finally, endometriosis may affect survival through improved treatment outcomes. Although the association did not reach statistical significance, most likely due to a small sample size, we did observe a non-significant decreased odds of platinum resistance among women who reported endometriosis. Future research should investigate the potential mechanisms through which endometriosis improves survival after an ovarian cancer diagnosis.

A recent pooled analysis of 52 epidemiological studies observed a significant increased risk of ovarian cancer with current HT use, particularly for serous and endometrioid tumours (Beral et al, 2015). Although HT increases risk of certain tumour subtypes, it may lead to less aggressive tumours, as we observed that longer duration of pre-diagnosis HT use was associated with a decreased risk of death. These results are similar to those observed in a large European cohort study (Besevic et al, 2015) that observed a $30 \%$ (95\% CI: 0.50-0.99) decreased risk of death from ovarian cancer for 5 or more years of HT use. In addition, a smaller study noted a decreased risk of death with HT use among ovarian cancer patients who had optimal tumour debulking (Hein et al, 2013). In contrast, most smaller studies did not observe an association between prediagnostic HT use and survival, although they had limited power and few cases with longer duration of use (Mascarenhas et al, 2006; Nagle et al, 2008; Wernli et al, 2008; Zhang and Holman, 2012; Felix et al, 2015). Interestingly, similar associations of improved survival with HT use have been noted for breast cancer, with potential mechanisms including hormonal influences (Christante et al, 2008; Sener et al, 2009). Ovarian tumours that develop among long-term users of HT may be more likely to express PR, which as noted above has been associated with improved survival (Sieh et al, 2013). Better understanding the interplay between hormone exposure and ovarian tumour development may elucidate novel mechanistic pathways in survival. However, we cannot exclude the possibility that long-term HT users may be diagnosed with ovarian cancer at an earlier stage due to increased interaction with health care professionals compared with never HT users.

In our study, cases with an older age at menarche or an older age at natural menopause had worse survival. Interestingly, the association for older age at menarche and overall survival appeared to be strongest among women with high-grade serous, endometrioid and clear cell tumours but was null among women with lowgrade serous tumours. Contrary to our findings, two studies have 
Table 4. Association between reproductive and hormonal factors and platinum-resistance among invasive ovarian cancer cases with a complete response to first-line platinum chemotherapy in the NECC $(n=449)$

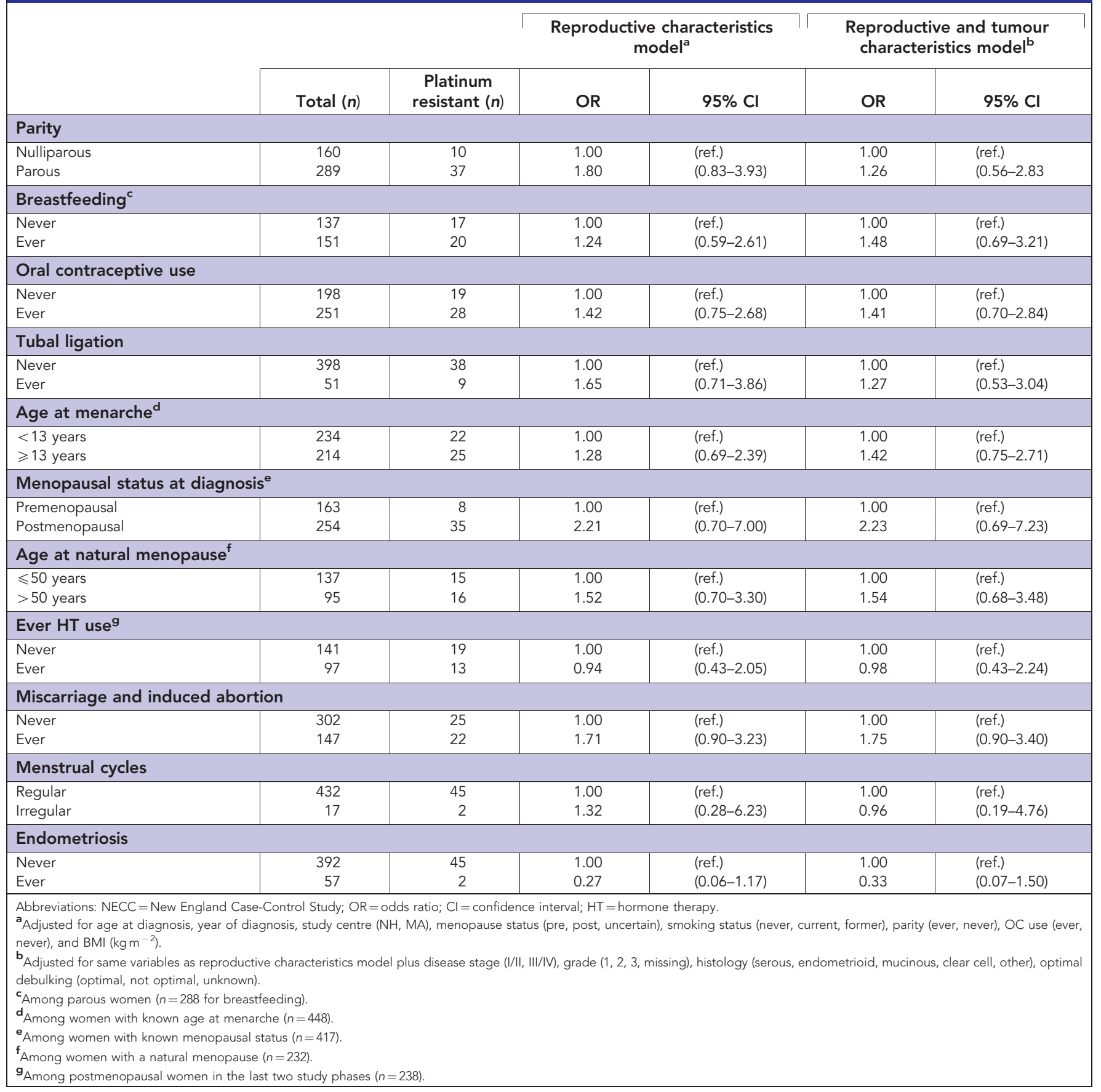

reported improved survival with older age at menarche (KjaerbyeThygesen et al, 2006; Robbins et al, 2009), whereas the majority of studies observed no association (Jacobsen et al, 1993; Mascarenhas et al, 2006; Nagle et al, 2008; Yang et al, 2008; Zhang and Holman, 2012; Besevic et al, 2015). In addition, all other studies that have assessed age at menopause and survival among ovarian cancer cases have reported null findings (Jacobsen et al, 1993; Mascarenhas et al, 2006; Yang et al, 2008; Besevic et al, 2015). Given the overall weight of the evidence, it is likely that our results were due to chance.

Only one other study has assessed abortion and survival among ovarian cancer cases (Jacobsen et al, 1993). In contrast to our findings of an increased risk of death with at least one spontaneous miscarriage, Jacobsen et al, 1993 reported a protective effect on survival for two or more abortions. However, this study did not distinguish between induced and spontaneous abortions making it difficult to directly compare with our results. In addition, we are the only study, as far as we know, that has assessed menstrual cycle irregularity and overall survival. We observed a better prognosis among women who reported menstrual cycle irregularity. Future research is needed to validate both the miscarriage and menstrual cycle irregularity findings in our analysis.

Our platinum-resistance analyses were limited by a small sample size. Only $10 \%$ of ovarian cancer cases with a complete response to platinum-based chemotherapy had a recurrence within 6 months of ending treatment. However, the observed direction of effects was similar to those observed in the analysis of overall survival. Although this may be due, in part, to the worse outcomes 
for patients with platinum resistance, such research, in large datasets with detailed treatment and recurrence data, is crucial to identify the underlying pathways through which pre-diagnosis exposures may influence tumour aggressiveness and hence survival.

One limitation of our study is that we did not have information on cause of death; however, prior studies have shown that most deaths at least within the first 3 to 5 years after diagnosis are due to ovarian cancer (Poole et al, 2013; Besevic et al, 2015). Of the 554 deaths in the European Prospective Investigation into Cancer and Nutrition, 92\% were due to ovarian cancer over a mean follow-up of 3.6 (s.d. = 3.2) years (Besevic et al, 2015). In analyses restricted to the first 5 years of follow-up, we observed similar results to the main findings. In addition, cases were interviewed a median of 8.9 months (min 0.8 months, max 45.4 months) after ovarian cancer diagnosis. Therefore, women with rapidly fatal cancers would be less likely to be included in the study. However, when we restricted analyses to women interviewed within 1 year of diagnosis the results were similar to the main findings. There were also a limited number of ovarian cancer cases who had a complete response to platinum-based chemotherapy thereby limiting power to observe associations between reproductive factors and platinum-resistance. Furthermore, as we have repurposed the NECC case-control study into a survival study, we lack information on post-diagnosis exposure information; however, we have detailed information on pre-diagnosis exposures and tumour characteristics (Poole et al, 2016). Finally, a large number of statistical tests were performed in this study, therefore there is the possibility that at least some of the results we have observed may be due to chance.

Our study was one of the largest studies to date to assess prediagnostic reproductive and hormonal factors, and overall survival. The large sample size allowed us to assess effect modification by histology and age at diagnosis. In addition, we had detailed prediagnostic exposure and covariate information collected through in-person interviews and pathology reports to abstract tumour characteristics. Furthermore, for over half of the study population we had access to detailed medical information including chemotherapy, debulking status, and response to chemotherapy enabling us to control for chemotherapy use and assess predictors of platinum resistance.

Among ovarian cancer cases we observed improved overall survival among women with pre-diagnostic endometriosis and long-term users of HT, which may be through changes in the hormonal or immunological milieu of these women. Future research should focus on understanding the mechanisms through which pre-diagnostic endometriosis and HT use may improve survival after an ovarian cancer diagnosis. In addition, further research is needed to validate our findings for spontaneous miscarriage and menstrual cycle irregularity.

\section{ACKNOWLEDGEMENTS}

This project was supported by the National Institutes of Health (R01 CA054419) and the Department of Defense (W81XWH-10-1-0280). ALS was supported by Training Grant T32 HD060454 in Reproductive, Perinatal and Pediatric Epidemiology from the National Institute of Child Health and Human Development, National Institutes of Health. ALS and AB were supported by the Cancer Epidemiology Training Program (NIH T32CA09001).

\section{CONFLICT OF INTEREST}

The authors declare no conflict of interest.

\section{REFERENCES}

Anuradha S, Webb PM, Blomfield P, Brand AH, Friedlander M, Leung Y, Obermair A, Oehler MK, Quinn M, Steer C, Jordan SJ (2014) Survival of Australian women with invasive epithelial ovarian cancer: a population-based study. Med J Aust 201(5): 283-288.

Attia GR, Zeitoun K, Edwards D, Johns A, Carr BR, Bulun SE (2000) Progesterone receptor isoform A but not $\mathrm{B}$ is expressed in endometriosis. J Clin Endocrinol Metab 85(8): 2897-2902.

Baldwin LA, Huang B, Miller RW, Tucker T, Goodrich ST, Podzielinski I, DeSimone CP, Ueland FR, van Nagell JR, Seamon LG (2012) Ten-year relative survival for epithelial ovarian cancer. Obstet Gynecol 120(3): 612-618.

Beral V, Gaitskell K, Hermon C, Moser K, Reeves G, Peto R. Collaborative Group On Epidemiological Studies Of Ovarian Cancer (2015) Menopausal hormone use and ovarian cancer risk: individual participant meta-analysis of 52 epidemiological studies. Lancet 385(9980): 1835-1842.

Besevic J, Gunter MJ, Fortner RT, Tsilidis KK, Weiderpass E, Charlotte Onland-Moret N, Dossus L, Tjonneland A, Hansen L, Overvad K, Mesrine S, Baglietto L, Clavel-Chapelon F, Kaaks R, Aleksandrova K, Boeing H, Trichopoulou A, Lagiou P, Bamia C, Masala G, Agnoli C, Tumino R, Ricceri F, Panico S, Bueno-de-Mesquita HA, Peeters PH, Jareid M, Ramon Quiros J, Duell EJ, Sanchez MJ, Larranaga N, Chirlaque MD, Barricarte A, Dias JA, Sonestedt E, Idahl A, Lundin E, Wareham NJ, Khaw KT, Travis RC, Rinaldi S, Romieu I, Riboli E, Merritt MA (2015) Reproductive factors and epithelial ovarian cancer survival in the EPIC cohort study. Br J Cancer 113(11): 1622-1631.

Christante D, Pommier S, Garreau J, Muller P, LaFleur B, Pommier R (2008) Improved breast cancer survival among hormone replacement therapy users is durable after 5 years of additional follow-up. Am J Surg 196(4): 505-511.

Felix AS, Bunch K, Yang HP, Arem H, Trabert B, Gierach GL, Park Y, Lowery WJ, Brinton LA (2015) Menopausal hormone therapy and mortality among women diagnosed with ovarian cancer in the NIH-AARP Diet and Health Study. Gynecol Oncol Rep 13: 13-17.

Garrett LA, Growdon WB, Goodman A, Boruta DM, Schorge JO, del Carmen MG (2013) Endometriosis-associated ovarian malignancy: a retrospective analysis of presentation, treatment, and outcome. J Reprod Med 58(11-12): 469-476. Gazvani R, Templeton A (2002) Peritoneal environment, cytokines and angiogenesis in the pathophysiology of endometriosis. Reproduction 123: 217-226.

Hecht JL, Kotsopoulos J, Hankinson SE, Tworoger SS (2009) Relationship between epidemiologic risk factors and hormone receptor expression in ovarian cancer: results from the Nurses' Health Study. Cancer Epidemiol Biomarkers Prev 18(5): 1624-1630.

Hein A, Thiel FC, Bayer CM, Fasching PA, Haberle L, Lux MP, Renner SP, Jud SM, Schrauder MG, Muller A, Wachter D, Strehl J, Hartmann A, Beckmann MW, Rauh C (2013) Hormone replacement therapy and prognosis in ovarian cancer patients. Eur J Cancer Prev 22(1): 52-58.

Howlader N, Noone AM, Krapcho M, Garshell J, Miller D, Altekruse SF, Kosary CL, Yu M, Ruhl J, Tatalovich Z, Mariotto A, Lewis DR, Chen HS, Feuer EJ, Cronin KAe (2015) SEER Cancer Statistics Review, 1975-2012. National Cancer Institute: Bethesda, MD, USA, Available at http://seer. cancer.gov/csr/1975_2012/based on November 2014 SEER data submission, posted to the SEER web site in April 2015.

Jacobsen BK, Vollset SE, Kvale G (1993) Reproductive factors and survival from ovarian cancer. Int J Cancer 54: 904-906.

Jayson GC, Kohn EC, Kitchener HC, Ledermann JA (2014) Ovarian cancer. Lancet 384: 1376-1388.

Kim HS, Kim TH, Chung HH, Song YS (2014) Risk and prognosis of ovarian cancer in women with endometriosis: a meta-analysis. Br J Cancer 110(7): 1878-1890.

Kjaerbye-Thygesen A, Frederiksen K, Hogdall EV, Glud E, Christensen L, Hogdall CK, Blaakaer J, Kjaer SK (2006) Smoking and overweight: negative prognostic factors in stage III epithelial ovarian cancer. Cancer Epidemiol Biomarkers Prev 15(4): 798-803.

Markman M, Bookman MA (2000) Second-line treatment of ovarian cancer. Oncologist 5: 26-35.

Mascarenhas C, Lambe M, Bellocco R, Bergfeldt K, Riman T, Persson I, Weiderpass E (2006) Use of hormone replacement therapy before and after ovarian cancer diagnosis and ovarian cancer survival. Int $J$ Cancer 119(12): 2907-2915. 
Melin A, Lundholm C, Malki N, Swahn ML, Sparen P, Bergqvist A (2011) Endometriosis as a prognostic factor for cancer survival. Int J Cancer 129(4): 948-955.

Nagle CM, Bain CJ, Green AC, Webb PM (2008) The influence of reproductive and hormonal factors on ovarian cancer survival. Int J Gynecol Cancer 18(3): 407-413.

Naik R, Nordin A, Cross PA, Hemming D, de Barros Lopes A, Monaghan JM (2000) Risk factors in stage III epithelial ovarian cancer: previous sterilisation is an adverse independent prognostic indicator. Eur $J$ Gynaecol Oncol 21(4): 357-361.

NCI (2015) Recurrent or persistent ovarian epithelial, fallopian tube, and primary peritoneal cancer treatment. In Ovarian Epithelial, Fallopian Tube, and Primary Peritoneal Cancer Treatment - for health professionals (PDQ). National Institutes of Health: Bethesda, MD, USA.

Noli S, Cipriani S, Scarfone G, Villa A, Grossi E, Monti E, Vercellini P, Parazzini F (2013) Long term survival of ovarian endometriosis associated clear cell and endometrioid ovarian cancers. Int J Gynecol Cancer 23(2): 244-248.

Pearce CL, Templeman C, Rossing MA, Lee A, Near AM, Webb PM, Nagle CM, Doherty JA, Cushing-Haugen KL, Wicklund KG, Chang-Claude J, Hein R, Lurie G, Wilkens LR, Carney ME, Goodman MT, Moysich K, Kjaer SK, Hogdall E, Jensen A, Goode EL, Fridley BL, Larson MC, Schildkraut JM, Palmieri RT, Cramer DW, Terry KL, Vitonis AF, Titus LJ, Ziogas A, Brewster W, Anton-Culver H, Gentry-Maharaj A, Ramus SJ, Anderson AR, Brueggmann D, Fasching PA, Gayther SA, Huntsman DG, Menon U, Ness RB, Pike MC, Risch H, Wu AH, Berchuck A (2012) Association between endometriosis and risk of histological subtypes of ovarian cancer: a pooled analysis of case-control studies. Lancet Oncol 13(4): 385-394.

Poole EM, Konstantinopoulos PA, Terry KL (2016) Prognostic implications of reproductive and lifestyle factors in ovarian cancer. Gynecol Oncol 142: $574-587$.

Poole EM, Merritt MA, Jordan SJ, Yang HP, Hankinson SE, Park Y, Rosner B, Webb PM, Cramer DW, Wentzensen N, Terry KL, Tworoger SS (2013) Hormonal and reproductive risk factors for epithelial ovarian cancer by tumor aggressiveness. Cancer Epidemiol Biomarkers Prev 22(3): 429-437.

Robbins CL, Whiteman MK, Hillis SD, Curtis KM, McDonald JA, Wingo PA, Kulkarni A, Marchbanks PA (2009) Influence of reproductive factors on mortality after epithelial ovarian cancer diagnosis. Cancer Epidemiol Biomarkers Prev 18(7): 2035-2041.

Sener SF, Winchester DJ, Winchester DP, Du H, Barrera E, Bilimoria M, Krantz S, Rabbitt S (2009) The effects of hormone replacement therapy on postmenopausal breast cancer biology and survival. Am J Surg 197(3): 403-407.

Siegel RL, Miller KD, Jemal A (2016) Cancer statistics, 2016. CA Cancer J Clin 66(1): 7-30.

Sieh W, Köbel M, Longacre TA, Bowtell DD, deFazio A, Goodman MT, Høgdall E, Deen S, Wentzensen N, Moysich KB, Brenton JD, Clarke BA, Menon U, Gilks CB, Kim A, Madore J, Fereday S, George J, Galletta L, Lurie G, Wilkens LR, Carney ME, Thompson PJ, Matsuno RK, Kjær SK, Jensen A, Høgdall C, Kalli KR, Fridley BL, Keeney GL, Vierkant RA, Cunningham JM, Brinton LA, Yang HP, Sherman ME, García-Closas M, Lissowska J, Odunsi K, Morrison C, Lele S, Bshara W, Sucheston L, Jimenez-Linan M, Driver K, Alsop J, Mack M, McGuire V, Rothstein JH, Rosen BP, Bernardini MQ, Mackay H, Oza A, Wozniak EL, Benjamin E, Gentry-Maharaj A, Gayther SA, Tinker AV, Prentice LM, Chow C, Anglesio MS, Johnatty SE, Chenevix-Trench G, Whittemore AS, Pharoah PDP, Goode EL, Huntsman DG, Ramus SJ (2013) Hormonereceptor expression and ovarian cancer survival: an Ovarian Tumor Tissue Analysis consortium study. Lancet Oncol 14(9): 853-862.

Urban RR, He H, Alfonso R, Hardesty MM (2016) Ovarian cancer outcomes: predictors of early death. Gynecol Oncol 140(2): 474-480.

Vitonis AF, Titus-Ernstoff L, Cramer DW (2011) Assessing ovarian cancer risk when considering elective oophorectomy at the time of hysterectomy. Obstet Gynecol 117(5): 1042-1050.

Wang S, Qiu L, Lang JH, Shen K, Huang HF, Pan LY, Wu M, Yang JX, Guo LN (2013) Prognostic analysis of endometrioid epithelial ovarian cancer with or without endometriosis: a 12-year cohort study of Chinese patients. Am J Obstet Gynecol 209(3): 241.e1-9.

Wernli KJ, Newcomb PA, Hampton JM, Trentham-Dietz A, Egan KM (2008) Hormone therapy and ovarian cancer: incidence and survival. Cancer Causes Control 19(6): 605-613.

Yang L, Klint A, Lambe M, Bellocco R, Riman T, Bergfeldt K, Persson I, Weiderpass E (2008) Predictors of ovarian cancer survival: a populationbased prospective study in Sweden. Int J Cancer 123(3): 672-679.

Zhang M, Holman CD (2012) Tubal ligation and survival of ovarian cancer patients. J Obstet Gynaecol Res 38(1): 40-47.

This work is published under the standard license to publish agreement. After 12 months the work will become freely available and the license terms will switch to a Creative Commons AttributionNonCommercial-Share Alike 4.0 Unported License.

Supplementary Information accompanies this paper on British Journal of Cancer website (http://www.nature.com/bjc) 